\title{
MUCOCELE DE SEIO FRONTAL COM EXPANSÃO INTRACRANIANA EM PACIENTE PEDIÁTRICO: RELATO DE CASO \\ Pôster
}

Autores deste trabalho:

João Pedro de Figueiredo Jordão Furtado de Mendonça: Hospital Infantil Cândido Fontoura

Rafaela Oliveira Tavares: Hospital Infantil Cândido Fontoura

Bruna dos Santos Ibiapina Neres: Hospital Infantil Cândido Fontoura

Mariana Aparecida Brunossi Moura Proença: Hospital Infantil Cândido Fontoura

Pedro Teles de Mendonça Neto: Hospital Infantil Cândido Fontoura

Maryana Beltrão de Carvalho: Hospital Infantil Cândido Fontoura

Ingrid Lacerda Pessoa: Hospital Infantil Cândido Fontoura

Lineke Gonçalves Dias: Hospital Infantil Cândido Fontoura

Área do Trabalho: Pediatria

Data da submissão: 10/08/2018 às $14: 43$

\section{Justificativa}

As mucoceles de seios paranasais são lesões císticas, benignas e expansivas, que ocorrem mais comumente em seios frontal e etmoidal, caracterizadas por período de evolução silenciosa de duração indeterminada, seguido de período de expansão, ocasionando deformidades e complicações locais.

\section{Objetivo(s)}

Este trabalho apresenta um relato de caso de mucocele de seio frontal em criança previamente hígida, manifestação rara na população pediátrica, com intuito de ampliar discussões acerca de lesões expansivas cranianas e seus diagnósticos diferenciais.

\section{Método(s)}

Relato de caso clínico com base em análise de prontuário e revisão bibliográfica acerca do diagnóstico principal.

\section{Resultado(s)}

E.C.S., masculino, 11 anos, admitido no pronto-socorro do Hospital Infantil Cândido Fontoura com queixa de cefaléia frontal, diária, de intensidade variável e progressiva há cerca de 30 dias, associada à vertigem de apresentação esporádica. Nega febre. 0 paciente apresentava abaulamento em fronte, com diâmetro aproximado de 4 centímetros, sem sinais flogísticos locais, amolecido e doloroso à palpação. Submetido a Tomografia de Crânio sem contraste, que evidencia lesão expansiva isodensa ao parênquima cerebral, de provável origem em seio frontal, com erosão óssea de calota craniana e expansão intra e extracraniana. Paciente avaliado pela equipe de oncologia clínica, sendo excluída hipótese neoplásica, e pela neurocirurgia, que opta por tratamento conservador. Paciente é mantido em antibioticoterapia 


\section{$4^{\circ}$ Congresso Internacional Saborá \\ 13 a 15 de \\ 13 a 15 de 2018}

venosa na unidade de origem com hipótese diagnóstica de mucocele infectada, com melhora evolutiva clínica e radiológica. Em nova avaliação pela equipe neurocirúrgica, opta-se por seguimento ambulatorial pela neurologia clínica e antibioticoterapia oral de longa duração.

\section{Conclusão (ões)}

A mucocele de seio paranasal, apesar de infrequente na população pediátrica, deve sempre fazer parte dos diagnósticos diferenciais de lesões expansivas cranianas, para intervenção precoce e prevenção de complicações. 